\title{
Radicalización y desradicalización de jóvenes yihadistas en Francia
}

\author{
Radicalization and deradicalization of young jihadists \\ in France
}

Iker Nabaskues Martínez de Eulate • iker.navascues@ehu.eus

UNIVERSIDAD DEL PAÍS VASCO/EUSKAL HERRIKO UNIBERTSITATEA

(UPV/EHU)

Recibido: $14 / 08 / 2017$

Aceptado: $17 / 10 / 2017$

\section{Resumen}

El presente artículo analiza el fenómeno de la radicalización yihadista en Francia. Primero me detengo en el enfoque general de algunos académicos franceses más importantes sobre las causas de esa explosión radical. En segundo lugar, desde una perspectiva menos generalista y estructural desgrano algunos elementos específicos relacionados con aspectos biográficos y sociales que determinan según los expertos, un proceso de radicalización. En tercer lugar, se hace una aproximación al panorama general de las políticas de desradicalización que se están implementando en nuestro contexto institucional: Unión Europea, países del entorno, Estado y Comunidades autónomas. En cuarto lugar, se presentan los aspectos más esenciales del Programa de desradicalización llevado a cabo por el gobierno francés en el año 2016 y el Programa CAPRI implementado en la ciudad de Burdeos. Finalmente en el apartado final se extraen una serie de conclusiones sobre el fenómeno de la radicalización yihadista y los programas de desradicalización en Francia a la luz de los datos extraídos.

Palabras clave: Radicalización, yihadismo, programas de desradicalización, islamismo radical, prevención.

\section{Abstract}

This article analyzes the jihadist radicalization phenomenon in France. Firstly, I analyze the general approach of some major French scholars about the causes of the explosion of radicalism. Secondly, I analyze from a specific approach, some of the social and biographical aspects of jihadist young people that determine, according to experts, a radicalization process. Thirdly, I make an approximation to the general outlook of de-radicalization policies in European Union, neighboring countries, Spain and autonomous communities in Spain. Fourthly, I analyze the main features of the De-radicalization program carried out by the French Government in 2016 as well as the CAPRI program implemented in the city of Bordeaux. Finally, I extract some conclusions about the jihadist radicalization phenomenon and De-radicalization programs in France in the light of the presented data.

Key words: Radicalization, Jihadism, De-radicalization programs, Radical Islam, prevention. 


\section{INTRODUCCIÓN}

El fenómeno de la radicalización yihadista ha pasado a formar parte central en de la agenda del gobierno francés desde los atentados terroristas de 2015. La explosión de violencia yihadista ha propiciado acalorados debates entre los expertos sobre el islamismo político. El hecho es que existen diferencias sensibles entre los académicos más reputados del país, sobre la interpretación sociológica de la realidad y los elementos que condicionan el fenómeno de la radicalización francesa. Algunos señalan la segregación y marginación de los barrios periféricos de las grandes conurbaciones urbanas de Francia como el caldo de cultivo para la aparición de los nuevos yihadistas, otros plantean que los jóvenes franceses pertenecen a una nueva yihad de tercera generación que actúa ejecutando una estrategia calculada por los líderes islamistas, que pretende hacer implosionar las sociedades occidentales desde dentro en base a sus propias contradicciones sociales. Hay académicos que señalan que la explosión de violencia es la consecuencia directa de la errática política internacional de Francia en Siria y el norte de Africa o que los yihadistas representan una nueva generación de nihilistas que odian a la sociedad y que adoptan la forma islamista como una cobertura ideológica de negación radical de las democracias occidentales. Todos ellos son elementos que son aludidos en la explicación de la violencia terrorista por parte de todos, pero hay académicos que priman unos matices sobre otros y en este punto radica la controversia intelectual.

En 2016 se puso en práctica un centro de desradicalización en Francia que no ha dado los resultados esperados. Distintas asociaciones civiles que trabajan en el ámbito de la prevención e intervención de la radicalización juvenil en el país desarrollan planes de intervención alejados de los postulados gubernamentales. El contraste entre dos tipos de programas muy diferentes respecto al abordaje del problema de la radicalización en Francia, permite comprender el fenómeno de la radicalización yihadista en toda su complejidad. En todo caso, la evaluación del plan de desradicalización del gobierno recogido en dos informes del senado del año 2017 - febrero y julio — señala hacia un cambio de rumbo en el modelo de intervención gubernamental.

Como en otros ámbitos de investigación, las definiciones del término radicalización abundan en el campo del terrorismo, pero no existe ninguna definición aceptada de manera unívoca, por lo que la creación de indicadores para medir la radicalización es en sí una tarea difícil. Otro punto importante para la investigación de la radicalización es la relación entre las creencias y el comportamiento violento. No está claro que las actitudes radicales impliquen directamente la acción violenta (Fishman, 2010: 10). El uso de herramientas de comunicación flexibles on-line como vía para la radicalización de individuos es un hecho notablemente popularizado en la última década con la extensión planetaria de internet, por lo que, llegar a comprender cómo son utilizados para captar jóvenes para la causa de la yihad, está resultando una cuestión esencial en el contexto de las políticas de desradicalización (Thompson, 2011: 167). 
La literatura existente destaca la escasez de investigaciones sobre los procesos internos y cognitivos inherentes a la radicalización pero también explicita que partiendo de las ciencias en educación, salud y rehabilitación, se puede llegar a comprender los procesos de radicalización. Esto ayuda a explicar cómo individuos no violentos puede llegar a aceptar, legitimar, y llegado el caso, ingresar en redes yihadistas (Wilnera y Duboulozb, 2010: 34). Hay autores que señalan algunas líneas de trabajo como prioritarias de las políticas de desradicalización: en primer lugar, conseguir deslindar una definición de la radicalización como un proceso separado del extremismo violento característico de los grupos terroristas; en segundo lugar, separar los procesos de desradicalización de otros objetivos de integración y cohesión social de naturaleza más generalista; en tercer lugar mejorar la formación especializada, la comunicación entre agentes de intervención, educativa, policial, social y sanitaria; por último focalizar el objetivo de los programas de desradicalización sobre personas con vulnerabilidades sociales, prescindiendo del enfoque teológico (Brandon y Vidino, 2012: 69).

El conocimiento sobre los programas de radicalización es todavía muy fragmentado y desigual, lo que hace que la evaluación comparativa de las numerosas iniciativas que se están implementando estos dos últimos años sea una tarea complicada. Pese a ello, el campo de la desradicalización se va desarrollando como consecuencia directa de la preocupación creciente provocada por los últimos atentados en suelo europeo, aunque se necesita tiempo para poder acometer análisis comparativos de resultados (Schmid, 2013: 55). La falta de claridad conceptual es uno de los principales obstáculos y se necesita aún de más investigaciones empíricas que generen nuevas evidencias con las que trabajar. Es difícil decir lo que funciona y lo que no funciona, o lo que es incluso contraproducente cuando se trata de radicalización y contra-radicalización. El contexto local importa mucho. En esta etapa, todavía carecemos de evaluaciones rigurosas que permitan determinar los méritos relativos de distintas políticas con un alto grado de certeza (2013: 61). El estudio de la radicalización requiere un enfoque analítico multifacético y una conceptualización muy matizada de los numerosos elementos que entran en juego en procesos de esta naturaleza (Schuurman et al., 2016: 16). Las estrategias desde enfoques generalistas, prescindiendo de que las causas que originan la radicalización obedecen a factores locales, cambiantes y circunstanciales, es contraproducente. Los estudios más recientes invitan a la formación especializada sobre radicalización así como a valerse del apoyo de los familiares de las personas radicalizadas en el futuro y a establecer itinerarios de reinserción de jóvenes que han llegado a integrarse en células yihadistas. Los estudios son cada vez más conscientes del precario apoyo que se ha prestado a la red familiar y cada vez se recalca que la familia es una institución fundamental que debe desempeñar un papel activo en un proceso de desradicalización (Parlamento Británico, 2016: 33). 


\section{FACTORES GENERALES QUE EXPLICAN LA RADICALIZACIÓN JUVENIL EN FRANCIA}

Los especialistas en el islam político han adquirido un peso muy importante en la arena política francesa como lo muestra la especial proliferación de publicaciones sobre la yihad francesa en 2016. ${ }^{1}$ Entre los autores que investigan las causas de la explosión yihadista juvenil destacamos en este artículo a Gilles Kepel, Olivier Roy, Jean Pierre Filiu, Francois Burgat, Fehti Benslama y Farhad Khosrokhavar. ${ }^{2}$

Gilles Kepel sostiene la tesis conocida en Francia como la «radicalización del islam.» Ubica el germen de una nueva generación de la yihad francesa en los años 2004 y 2005. ${ }^{3}$ Aunque en términos de idioma, educación y cultura pop los jóvenes de los suburbios eran jóvenes asimilados, no se sentían vinculados a la política nacional y pese a carecer de educación musulmana comenzaron a ser islamizados sobre las bases ideológicas del salafismo radical. Estos jóvenes constituyen una tercera generación de yihadistas franceses que descansa en la lógica de las redes, potenciada por la existencia de grupos similares en barrios desfavorecidos, por el reclutamiento en las cárceles y por la extraordinaria difusión de los espacios en internet para compartir videos (2016: 31).

Según Kepel, los servicios de inteligencia no previeron el surgimiento de una nueva generación de yihadistas que fueron guiados por la obra de Abu Moussab Al-Suri —Mustafá Setmarian-, ex miembro de los Hermanos Musulmanes y Al Qaeda, "Llamamiento a la resistencia islámica mundial» (2016: 67-68). ${ }^{4}$ Kepel alude a una motivación retrocolonial, cin-

\footnotetext{
1 El islam político fue objeto de estudio específico en Francia sobre todo a partir de la década de 1980. Los estudios sobre el islamismo comienzan como disciplina autónoma a partir del trabajo de Bruno Étienne, El islamismo radical (1987) y la obra de Gilles Kepel Los musulmanes extremistas en Egipto: El profeta y el faraón (1984). Hay que citar a otros islamistas de aquella década como Olivier Carré, Rémy Leveau, Michel Seurat, o Alain Roussillon. Los investigadores en este campo no se fundamentaron en hacer exégesis del Corán ni sobre las diferentes interpretaciones del islam sino que cimentaron su labor desde la ciencia política, la sociología o la historia del pensamiento. Sus estudios habían perdido interés en Francia pero sobre todo a partir de los atentados del 11 de septiembre de 2001, volvieron a ganar protagonismo, que se ha incrementado con los últimos atentados en suelo francés.

${ }^{2}$ Existen numerosos académicos franceses expertos sobre el islam político a los que hay que hacer referencia de manera obligada para un acercamiento científico a la materia. Algunos de ellos se mencionan en este artículo y otros no. Entre otros autores franceses destacados, además de los que se recogen en el cuerpo de este artículo, pueden citarse a Stéphane Lacroix, Alain Bertho, Samir Amghar, Nilüfer Göle, Bernard Rougier, Myriam Benraad, Laurent Bonnefoy, Vincent Geisser, Jean-Pierre Luizard, Nacira Gueif-Souilamas, Mohammed El Adraoui, David Thomson, Anna Erelle, Romain Caillet o Raphael Liögier entre otros.

${ }^{3}$ En 2004 se promulgó la Ley francesa sobre laicidad que prohibía la utilización en la escuela del hijab musulmán — velo que cubre la cabeza de las mujeres-, la kipá judía, el turbante sij o el mostrar símbolos cristianos de manera ostentosa, permitiendo únicamente el uso de símbolos religiosos discretos de cualquier religión a modo de colgante, pulsera etc. La cuestión creó controversia con la Unión de Organizaciones Islámicas de Francia puesto que la anterior regulación dejaba en las direcciones de los colegios la decisión final. El mismo Gilles Kepel participó como experto en uno de los grupos de discusión de la ley. Un año más tarde, en 2005, y en el contexto de la polémica generada por la ley, se produjeron las grandes revueltas en los banlieues, como consecuencia de la muerte de dos jóvenes electrocutados en su huida de la policía en Clichy, en los suburbios del extrarradio de París y que más tarde se extendieron por toda Francia. Para Kepel, estas revueltas, que tuvieron un impacto mediático enorme, cristalizaron en una nueva conciencia en jóvenes musulmanes franceses que se sintieron atraídos por un lenguaje fundamentalista con una fuerza nunca vista en generaciones anteriores (Kepel: 2016, 51-81).

4 Al-Suri, sirio de nacimiento y que posee la nacionalidad española, fue el responsable de la sección de relaciones exteriores de Al-Quaeda y como tal tuvo un papel en el máximo nivel, en la elaboración de los planes para
} 
cuenta años después del final de la Guerra en Argelia, como elemento coadyuvante de la nueva generación de yihadistas. Una generación de jóvenes franceses que se conecta de manera imaginaria a un tiempo que no conoció. Este vínculo imaginario persigue su hipotética venganza por el desprecio de Francia para con sus padres y abuelos, en un contexto de auto-minusvaloración de la comunidad francesa respecto al resto de ciudadanos (Khosrokhavar, 2015). Los yihadistas de tercera generación, crecidos en el clima de marginalidad de los suburbios y con grandes carencias afectivas, se creen con legitimidad para proceder a un ajuste de cuentas generacional, pese a que han nacido en Francia, han estudiado en la escuela francesa y se han beneficiado de las ayudas sociales del Estado de bienestar (Kepel, 2016a). Los líderes e imanes salafistas radicales promovieron en ese caldo de cultivo, la segregación cultural de los jóvenes de los barrios relegados y comenzaron a aplicar la sharia — ley islámica — en los suburbios por la vía de hecho.

Kepel otorga a la ideología salafista una importancia crucial en la estructuración de la personalidad de estos jóvenes. ${ }^{5}$ El salafismo se plantea como ideario de ruptura y negación de los valores republicanos y occidentales e impide, por su rigorismo político, que otras tendencias del islam mayoritarias y no violentas puedan influirles. Con el fin de la sociedad industrial estos jóvenes en paro no se ven reconocidos en los instrumentos de representación política. Los conflictos, estandarizados en base a la dialéctica izquierda-derecha, enfrentan ahora a una sociedad global universal y a la dicotomía entre el islam y el republicanismo francés que alimenta el fundamentalismo islámico y su reacción por medio del Frente Nacional. Estas transformaciones «redefinen las pertenencias de grupo y la comunidad imaginaria con la que sus adeptos se identifican, es transversal y heterogénea y se suma a una ética de sustitución de certezas morales que se enfrenta a una política institucional corrupta» (2016: 39).

Tras los atentados de noviembre de 2015, el académico Olivier Roy salió a la palestra refutando abiertamente la tesis de Kepel en un breve ensayo publicado por Le Monde. Roy invierte la tesis de Kepel y sostiene la tesis de la «islamización de la radicalidad» (2015: 4). Para Roy los nuevos yihadistas franceses proceden de la periferia del mundo musulmán y no han frecuentado la mezquita. Rompen con la sociedad desde un nihilismo que se adapta a las consignas yihadistas con la promesa de un paraíso, pero solamente como un elemento que ennoblece un profundo impulso nihilista. Los jóvenes encarnan una ruptura generacional contra la forma de vida de sus padres y contra la forma de vida occidental en la que el salafismo les atrae como cobertura radical, pero no como una ideología que oriente sus acciones. Los jóvenes franceses no aspiran a una islamización de la sociedad

el atentado del 11-S. apela en su obra, al «terrorismo por imitación» donde la confianza, la amistad, el lugar de procedencia o el parentesco son los elementos de conexión e identidad de las células de intervención (Instituto Español de Estudios Estratégicos: 2014). Anima a los nuevos integrantes de la yihad a atacar objetivos civiles en sus países de origen creando el caldo de cultivo para el enfrentamiento social en las sociedades occidentales en base a la contradicción islamofobia-multiculturalismo acentuada por los atentados en suelo occidental (2016b: 75-76).

${ }^{5}$ El salafismo contiene varias corrientes en su propio seno y se asocia a menudo, de manera equivocada, con la violencia cuando los estudios de los expertos coinciden en que la corriente que aboga por ella, es muy minoritaria (Castien, 2010, Burgat 2010, Al-Adraoui, 2013 o Suárez Ballester, 2016). 
sino a la materialización de una fantasía heroica que sirve de cobertura a una violencia destructiva de carácter esencialmente nihilista (2016: 15).

Estaríamos según Roy, ante una revuelta nihilista, donde el fundamentalismo religioso es una reacción defensiva de reconstrucción de una identidad religiosa en una situación de crisis de identidades provocada por la globalización (2016a). La religión no es más que la forma con la cual aparece el conflicto, cuyo origen hay que buscarlo en las fallas del sistema institucional francés. Para Roy, los jóvenes franceses que se enrolan en el Estado Islámico no creen en el proyecto político de esa organización (2015: 5). Los jóvenes carecen de un planteamiento religioso que luego bascula hacia la violencia sino que es su nihilismo el que adopta una forma religiosa donde el salafismo es una simple capa exterior. La asunción de la muerte como parte de la narrativa yihadista les aleja de otro tipo de terrorismo político donde se produce una maximización del militante y donde el esquema ideológico adquiere una importancia central (2016: 10-35).

La conversión religiosa de los yihadistas franceses se produce de manera fulgurante y jamás en el marco de una organización religiosa. Los jóvenes ignoran los movimientos políticos y religiosos de la época colonial, no han participado en movimientos contra la islamofobia o en ONGs a favor de la causa palestina (2015: 5), no son utopistas implicados en la lucha social sino que deciden dar el paso a la yihad por emulación con amistades pertenecientes a redes precedentes (2016a: 18). Para Roy lo que vincula a casi todos los jóvenes yihadistas franceses es la sublimación de la muerte, "producida en una explosión final por la que un héroe solitario y vengador se libera de la dominación y humillación a la que le ha sometido el sistema republicano» (2016a: 19). No son milenaristas, son nihilistas modernos para los que la muerte es un fin de trayecto sublimado (2015: 15). El éxito del Daesh es aportar un marco de posibilitamiento de esta opción nihilista en la que el salafismo, y no el islam, actúa como ideología de ruptura y como la opción de tabula rasa que funciona como la cobertura de la sublimación de la muerte. La violencia es un fin, no es un medio para un proyecto político, puesto que para Roy «estos jóvenes no están interesados ni en el islam, ni en el sufrimiento provocado a los países musulmanes (2016a: 19-20).

A pesar de estas diferencias de fondo, existe un nexo de unión entre Kepel y Roy. Ambos fundamentan la irrupción de la violencia yihadista en una lógica hexagonal francesa y en relación a fenómenos sociales endógenos. El enfoque de Francois Burgat y Jean-Pierre Filiu en cambio, se fundamenta en los errores de la política internacional francesa, fundamentalmente en el apoyo a los regímenes dictatoriales de Africa del Norte y Oriente Medio y en la errónea interpretación del gobierno francés de la crisis revolucionaria de los países árabes en el 2011. Francois Burgat ve en la teoría de Roy una pretensión de despolitizar las motivaciones de los actores de la yihad francesa y propone el acercamiento al fenómeno desde un enfoque político y global, que es el que permite entender la erupción de la violencia juvenil como el resultado de factores geopolíticos, sociales y aspiraciones de emancipación directamente ligados a ellos. El salafismo radical francés sería así, la respuesta de los oprimidos «a unas políticas coloniales que se transformaron en globales» (Dakhli, 2016: 
24). Para Burgat, negarse a interpretar el fenómeno desde el panorama político árabe y de las políticas de Occidente respecto al Tercer Mundo, atribuyéndole un carácter de rebelión nihilista plantea más problemas de los que resuelve (2016: 15).

Desde esta premisa, para comprender el origen de la erupción de la violencia y de la radicalización juvenil, hay que examinar las circunstancias esencialmente políticas (injerencias militares occidentales en países árabes, complacencia con dictadores de aquellos países, la marginación, la represión o la tortura inflingida a jóvenes franceses excluidos de los suburbios...) que han fabricado actores deseosos, «no tanto de usar el Islam para justificar su conducta, como de considerar la violencia como la única respuesta posible ante su situación» (2016: 25) Burgat, desde un enfoque bourdieuano, no cree en la autonomía de la locura de los jóvenes franceses que más bien serían los outsiders de un sistema de dominación que ha logrado imponer sus propias reglas (Dakhli, 2016: 25).

El desacuerdo de Burgat con Kepel aún es más profundo dado que éste apunta que el salafismo atenta contra los axiomas más básicos y fundamentales de la República (Burgat, 2016: 210) El problema para Burgat es la propia interpretación sectaria y unilateral que se hace sobre los valores de la República francesa que propicia que «quienes están en una situación geopolítica de dominación tienden a preferir aquellas explicaciones del fenómeno que le exoneran de su propia responsabilidad» (2016: 29). Para Burgat las reacciones islamistas de hoy tienen un peso identitario que descansa en la lógica de los procesos de descolonización y la interpretación hexagonal del problema es el velo que cubre el análisis de profundos desequilibrios provocados por la escena política mundial. Desde este punto de vista, cualquier solución debería pasar por «proceder a la deconstrucción de las disfunciones que cimentan las estructuras de la explosión de la violencia en Francia (2016a).

Jean Pierre Filiu al igual que Burgat, relaciona los atentados en Francia con las desestabilizaciones geoestratégicas que han propiciado la crisis de seguridad generalizada en los países occidentales (2015: 65). Para Filiu «estamos ante conflictos importados al territorio francés desde Argelia, Siria o Irak y no de la aparición de una «yihad francesa» ya que detrás de la red francesa, aún y cuando se erija en torno al principio de descentralización, lo que le permite un gran poder de maniobra, «siempre hay una orden de Oriente Medio» (2015a: 16) El gran error de Francia, y de Occidente por extensión, sería el haber permitido desarrollar todo un poder yihadista en el propio territorio, «pensando que la violencia quedaría relegada a oriente próximo (2015: 64). Desde este enfoque la explosión de violencia en Francia no hay que buscarla en textos teológicos sino en la política exterior de los países occidentales y en la exclusión socioeconómica de los suburbios, cimentada por un abandono institucional agravado con el paso de los años. Los jóvenes yihadistas serían «la primera generación posthistórica» (Bertho, 2016: 104) ante el final de la política como potencia subjetiva para abrir nuevos disensos y propiciar nuevas narrativas de emancipación (Bertho, 2016: 206).

El psicoanalista y académico Fehti Benslama afirma que sociológicamente, gran parte del fenómeno de la radicalización yihadista está vinculado a la pérdida de esperanza que se 
incuba en los suburbios de las ciudades francesas. Falta de integración social para los jóvenes de familias migrantes y musulmanas, carencia de horizontes de vida para otros jóvenes que viven de empleos precarios, carencias educativas y fuertes presiones de una sociedad de consumo que «ofrece mucho pero no proporciona los recursos suficientes para adquirir su oferta» (2015). La desesperación es el resultado de la ausencia de esperanza y la carencia de perspectivas. En esta etapa de la vida, los jóvenes viven profundos ajustes en su identidad y buscan ideales para orientar su acción, los ideales enlazan lo individual con lo colectivo en la formación del sujeto. La oferta de la yihad capta a unos jóvenes angustiados por su identidad y se transforma en un ideal total que colma sus fallas y les permite reparar su condición de desplazados. La creencia religiosa constituye una coraza sobre la que no existe duda alguna. En este encuentro con un ideal absoluto, «se pasa de sentirse nada a sentirse todo y la fragilidad de la identidad deviene un blindaje poderoso cuando la juventud se viste con ese ideal. La angustia se alivia, se produce un sentimiento de liberación de los males de este mundo y de omnipotencia, con la desaparición de la individualidad, fusionada en un ideal histórico religioso muy grande.» De esta manera, el islamismo radical se presenta como la solución a los problemas de la existencia — soledad, comunicación, marginación, pobreza y hasta de la propia muerte- (2015).

Casi siempre los reclutas del yihadismo francés son perfectos analfabetos en materia religiosa y ha habido casos en que entre sus pertenencias se han encontrado libros como L'Islam pour les nuls, - Islam para ignorantes - una introducción a la religión musulmana (2015). Se trata de personas que «buscan la radicalización, antes incluso de encontrar el producto». La salida para el mártir de la fe, es un camino en el que se siente poderoso porque pone en jaque a los aparatos represivos más sofisticados del Estado. El mártir es alguien que busca sobrevivir desapareciendo, llevando a cabo un auto-sacrificio de transferencia hacia un ideal absoluto (2015).

Pese a estas connotaciones, para Fehti Benslama, la explicación psicopatológica es insuficiente. Distingue tres grupos de personas terroristas: los «idealistas fanáticos», los «delincuentes» y por último, un grupo minoritario de personas que sufren una enfermedad mental. La reducción del radicalismo yihadista a una cuestión psicopatológica es un error. La pretensión de identificar una causa como principal para el fenómeno de la radicalización está abocada al fracaso teniendo en cuenta su complejidad y causas multifacéticas que la originan (2017).

El mito sacrifical y de salvación de los yihadistas, que opera de manera paradójica contra la ortodoxia suní, lleva al activista a considerarse el «más musulmán de los musulmanes». Roy afirma que «al verse a sí mismos de esa manera, reivindican su pureza musulmana por encima de la de sus padres.» (2015: 6). Benslama ha teorizado este peculiar fenómeno identitario con la tesis del «surmusulman»: «El mártir no es el que toma el riesgo de morir en combate sino el que se sacrifica matando el máximo de enemigos. El surmusulman que se compromete en organizaciones yihadistas está convencido que la muerte es su gran y última recompensa» (2016: 82). 
Para Benslama, todas las generaciones en el mundo musulmán, desde el final de la «llamada colonial», en la segunda mitad del siglo xx, han sido formadas por una guerra de subjetividades, cuya radicalización comienza en la década de los setenta y continúa hoy en día (2014). Benslama describe un mundo musulmán enfrascado en una "guerra de subjetividades». Para los yihadistas, ser musulmán significa «imponer una definición de los musulmanes» a todos los que viven en la «tierra del islam», que no es un lugar geográfico, sino cualquier parte del territorio donde viven los musulmanes. Los nuevos yihadistas asumen el poder "para asumir el privilegio de hablar en nombre del islam» y algunos movimientos islamistas más minoritarios y rigoristas ven a los yihadistas como una recuperación de la antigua definición original del musulmán de hace catorce siglos (2015a: 14-15). Son los surmusulmanes, jóvenes que se convierten en yihadistas de guerreros para vengar el «ideal herido" y "la deidad ultrajada" y así reactivar la Umma — comunidad musulmana(2015a: 27). Benslama deconstruye, con la encarnación del «surmusulman», el islamismo radical partiendo del psicoanálisis, , identificación reactiva que lleva a adoptar una lógica de sobre-identificación del ideal musulmán, tomándolo como un absoluto a-histórico. Esta identificación es crucial para entender el proceso de radicalización según Benslama. El surmursulman se convierte en un imaginario absoluto, en un horizonte mental que estructura la totalidad del «individuo ideal» y que se convierte en un motor legitimado moralmente para la crueldad.

Farhad Khosrokhavar diluye el hecho de que los jóvenes de los suburbios sean los protagonistas de la yihad, ya que el $20 \%$ de los yihadistas pertenecen a familias de clase media (2015a: 30). Muchos jóvenes de clases medias, no son condenados al ostracismo social, tienen trabajo y sin embargo muchos de ellos se radicalizan (2015a: 31). Khosrokhavar pone el acento en un odio de la sociedad ${ }^{6}$ que proviene del sentimiento de sentirse víctimas de una profunda injusticia social que en muchos casos, se muestra con mayor virulencia tras el paso por la prisión, estancia que profundiza el desarraigo social hasta la exclusión social. La célula yihadista, con una nueva disciplina de vida y la violencia de su ruptura con la sociedad ofrece un fascinante horizonte futuro, un calor compartido en la esperanza de una nueva comunidad marcada por el sello sagrado de la identidad. Para Khosrokhavar, la estancia en prisión es uno de los catalizadores más potentes de radicalización. La prisión lejos de ser el vehículo de reinserción del individuo en la comunidad, convierte el delincuente de poca monta en un guerrero listo para el combate (2015a: 41).

Khosrokhavar definió la radicalización en 2014 como «un proceso por el cual un individuo o un grupo adopta una forma de acción violenta, directamente ligada a una ideología extremista de contenido político, social o religioso, que desafía el orden establecido por medio de un programa político, social o cultural» (2014: 8). Esta noción de radicalización fue

\footnotetext{
${ }^{6}$ Amélie Boukhobza ha investigado la construcción imaginaria del judío en el discurso yihadista y se basa en el trabajo de campo con jóvenes delincuentes suburbanos y con padres de yihadistas. De las entrevistas y su análisis se desprende «el odio al judío», que se repite en el discurso extremo del islamismo. Esta construcción del judío como «conspirador satánico que manipula todos los agentes mundiales contra el islam, parece hoy alcanzar una virulencia nueva y alarmante» (2015: 127).
} 
objeto de muchas críticas y debates dentro y fuera de la comunidad científica. Khosrokhavar ha analizado estos últimos años los diversos mecanismos y procesos sociológicos contemporáneos de radicalización yihadista, y pese a que, como se ha expresado en líneas anteriores, no existe un itinerario común para describir un proceso de radicalización, hace hincapié en algunos elementos recurrentes como son: el sentimiento de victimización, la adhesión total a una causa colectiva, el odio a la sociedad y la cárcel como lugar de reclutamiento idóneo.

Los enfoques de Kepel y Roy apuntan a un enfoque exclusivamente francés de las políticas públicas como solución al problema de la radicalización. Kepel señala el combate ideológico al salafismo en los banlieues como un elemento clave para frenar la yihad francesa. Roy, en sentido inverso, prioriza el abordamiento psicológico y psiquiátrico del porqué los jóvenes abandonados, pero plenamente occidentalizados, de los suburbios tienen esa fascinación por la violencia y la muerte. La posición de Burgat y Filiu, desde una visión poscolonial de izquierda, aboga por extraer conclusiones de la interacción de la política exterior francesa con los procesos de marginación en los barrios. Benslama y Khosrokhavar se fijan en aspectos psicológicos y biográficos de los jóvenes como son la búsqueda de una identidad radical o el odio a la sociedad y la estancia en prisión como elementos definitorios. Este panorama refleja un panorama bastante plural por parte de los expertos, lo que condiciona la orientación de las políticas públicas en Francia.

\section{FACTORES ESPECÍFICOS QUE EXPLICAN LA RADICALIZACIÓN JUVENIL EN FRANCIA}

Otra experta que ha estudiado la radicalización yihadista es la antropóloga social y directora del Centro de Prevención de las Derivas Sectarias Relacionadas con el Islam, ${ }^{7}$ Dounia Bouzar. Bouzar define la radicalización como un «método de reclutamiento relacional e ideológico, en el que un grupo provoca en el joven una adhesión a una nueva comunidad social e ideológica.» Esas dos dimensiones están según Bouzar estrechamente unidas puesto que la «convicción de poseer el verdadero islam es el punto que amalgama al grupo» (2016: 83). La adhesión se logra por medio de una teoría de la conspiración por la cual el joven tiene el sentimiento de que todo el mundo es cómplice de una sociedad secreta que se guarda el poder y la ciencia para ella. «Esto acelera la sensación de incertidumbre del joven en relación al mundo, lo que acelera la necesidad de poner orden y estructurar el mundo a través de medidas compensatorias» (2016: 84). La teoría de la cons-

\footnotetext{
7 El centro de Bouzar (CPDSI) estuvo muy ligada a los programas del gobierno. En marzo de 2015 el Ministerio del Interior contrató con su centro algunos programas de intervención socio-pedagógica. En abril de 2016 Bouzar anunció que no renovaría ningún programa más con el gobierno francés por causa del progresivo endurecimiento de la legislación terrorista en Francia que plantea la privación de la nacionalidad francesa para los involucrados en redes yihadistas. Para Bouzar este tipo de medidas creaba un contexto desfavorable para la prevención pedagógica y científica de la radicalización en Francia (Le Monde, 2016). La información sobre el Centro está a disposición en http://www.cpdsi.fr/.
} 
piración como generadora de ansiedad y discurso radical como solución a esa misma ansiedad están para Bouzar indisociablemente unidas.

Para Gerald Bronner, no existe ningún tipo de indicador que nos induzca a creer que los jóvenes franceses ingresan en la yihad debido a motivos psiquiátricos (2016). Según Bronner, la teoría de la conspiración es muy seductora para jóvenes con unas determinadas características sociales, «el joven da la impresión de ser más inteligente que otros que le rodean, lo que le da una plusvalía en el espacio social y le permite poner en coherencia toda una serie de acontecimientos que ni siquiera le concernían. Cuando el joven se la cree, suscita tal indignación moral que le hace soñar en una revolución» (2016a). Existen recientes estudios que avalan el nexo entre la asimilación de la teoría de la conspiración y la generación de pensamientos extremos en el individuo (Van Prooijen eta al., 2015), en línea de lo que afirma Bronner.

En medio del proceso de creación de incertidumbre y adquisición de certidumbres por medio de la asimilación de la ideología radical yihadista, se producen las rupturas sociales, escolares y familiares que facilitarán este proceso (Bouzar, 2016: 84-85). La claridad y la conciencia del joven depende en gran medida de sus aptitudes personales como de la existencia de una red sociofamiliar de apoyo lo suficientemente sólida como para parapetarse en ella antes las contradicciones generadas por el proceso de radicalización. La lectura paranoica del yihadismo penetra mucho más fácilmente en un joven debilitado como consecuencia de una historia familiar difícil o a acontecimientos traumáticos sufridos en su vida (2016: 85). El grupo yihadista llena el vacío afectivo producido en realidades sociales comunes a los suburbios de las grandes ciudades. Se reprocha a los padres, el no haber sabido transmitir una religión verdadera y haber optado por la no confrontación con una sociedad que se desaprueba, lo que propicia el alejamiento intergeneracional con los padres. La ausencia de figura paterna y el debilitamiento del vínculo materno son elementos habituales en la vida de los yihadistas franceses. La lógica del joven se instala en una lógica hiperindividualista que se manifiesta en la desintegración con las estructuras sociocomunitarias (Al Adraoui, 2015: 18-19).

Existe, siguiendo el marco teórico con el que trabaja el CPDSI, un proceso secuencial en un proceso de radicalización. Para Bouzar «conocer el método en que estas personas son apartadas de su ambiente originario y convertidas en títeres del fanatismo ayuda a entender el modo en que se las puede desenganchar de ese mundo» (2016a: 20). La radicalización se produce según Dounia Bouzar en cuatro etapas (2016a: 21-22).

1. Desgajar al individuo de su familia y entorno. El discurso de adoctrinamiento a través de internet ${ }^{8}$ de que vive en una sociedad que le engaña provoca dudas e incertidumbre

\footnotetext{
${ }^{8}$ La influencia de portales yihadistas sobre la nueva generación de la yihad es un hecho sobradamente conocido. Asiem El Difraoui explica el cuidado y detalle con el que se producen los videos del Estado Islámico: «los movimientos de cámara salen de los videoclip musicales. Los cantos de guerra a capella, los anashid (música vocal musulmana) adoptan el código y el lenguaje del gangster-rap para enganchar a los «nativos digitales, hi-
} 
en el joven. El joven deja de frecuentar a sus amigos a quienes considera ciegos, con sus actividades recreativas que le parecen vacuas. Rompe con la escuela y finalmente con la familia a quien considera sujetos aletargados por el sistema.

2. La destrucción del individuo. El joven recibe el mensaje de que el genuino islam posibilita el despertar y discernimiento. El individuo es engullido por el grupo. La nueva vestimenta permite que se borre su individualidad. El efecto a medio plazo es borrar los recuerdos y las emociones de su vida. En este punto, el intentar disuadir al joven es ya una tarea imposible.

3. Adhesión a la ideología radical yihadista. El grupo ostenta la pureza y primacía. El joven no debe mezclarse con nadie más. El profundo sentimiento de injusticia social de la que se cree víctima el joven permite el tránsito al «odio de la sociedad» (Khosrokhavar, 2016: 277).

4. Deshumanización. Quienes no quieren despertar y regenerarse no son humanos. Matarlos no es un crimen sino un deber. La crueldad y la banalización de la violencia son el vehículo para anular el concepto de humanidad que queda en la persona.

Bouzar defiende que cualquier proceso de desradicalización debe basarse en un acompañamiento personal a la víctima desarrollado desde un plano emocional y no racional. El proceso de desradicalización debe buscar la reconstrucción de los vínculos afectivos entre la víctima y su familia (2016a: 20). La ayuda familiar en ese proceso es crucial, recuperando episodios de vida en los que la víctima manifestaba un vínculo con ellos, por ejemplo mediante fotos, videos, etc. Lo fundamental es «hacer resurgir la antigua identidad perdida (2016a: 23). El contexto privado, emocional y personal es el único que puede ofrecer garantías de éxito. Para Bronner, «toda desradicalización tiene que ser una auto-desradicalización», por la que el sujeto abandona una adhesión incondicional por su propio discernimiento (2016b). Frente a una vivencia de este tipo, el elemento básico es que la víctima recupere su espíritu crítico por medio de vivencias propias y privadas.

Uno de los aspectos cruciales es lo que Bouzar denomina la «actualización de las contradicciones de la víctima» (2016: 24). El CPDSI emplea el testimonio de personas exreclutadas para que la joven o el joven tomen conciencia de los mecanismos de captación de los que han sido víctima. El exreclutado ${ }^{\text {} ~}$ confronta el desfase del discurso del DAESH —acró-

jos de Occidente que han crecido con el rap y el pop» (2014: 24). Estos vídeos funcionan en torno a tres niveles: en primer lugar, se muestran acciones militares para convencer a los posibles reclutas. Después, se elabora una gran narración entorno al ejemplo de Mahoma y sus primeros compañeros, mostrando un simbolismo islámico basado en el sable del profeta, la bandera negra de la guerra, el Corán y la vestimenta de la época del profeta. Finalmente, se construye una escatología del mártir, un mito de salvación en las que los más nobles son aquellos que se sacrifican en el combate y más todavía en ataques suicidas (2014: 24-26).

${ }^{9}$ Un reciente estudio explica que los testimonios de los exreclutados pueden ser un recurso muy poderoso en los planes de desradicalización. Así, detalla que el testimonio del exreclutado rompe la unidad de discurso que busca transmitir el grupo yihadista sobre el reclutado; la narración del exreclutado destaca las contradicciones del ideario del grupo; pone a la luz que las promesas nunca se cumplen y alienta a los reclutados a desgajarse del grupo. El informe recomienda a los gobiernos y los activistas que trabajan en el ámbito de la desradicali- 
nimo del Estado Islámico en árabe-y la realidad que le espera al joven, y la víctima se ve reconocida en ese discurso. Al no saber en quien confiar se crea una duda saludable. Para Bouzar este punto es clave en el proceso de desradicalización. Solo el exreclutado es capaz de introducir dudas e incertidumbre en el nuevo discurso construido por la víctima (2016a: 25). El exyihadista Farid Benyettou, que fue imán salafista y mentor de los hermanos Kouachi, autores del atentado sobre la revista satírica de París, ha colaborado con el centro de Bouzar lo que provocó gran controversia con asociaciones de víctimas francesas que mostraron su rechazo a que un exconvicto participase en este tipo de procesos. Sin embargo su labor en los procesos de desradicalización es elogiada en el libro blanco del CPDSI, donde se expresa que: «la introspección entre pares es una herramienta que proporciona resultados muy buenos para el interés de la investigación científica, mucho más que el empleo de estrategias de contradiscurso" (Bouzar, 2016b: 5). Por medio del grupo de apoyo con la participación de exreclutados se realiza una revisión crítica de las convicciones que pueden ayudar a la reconstrucción del yo, mediante el fomento de la reflexión, la duda y la conversación. Es solo cuando el joven o la joven es capaz de construir un análisis propio y cuando puede vivir un «desplazamiento emocional y cognitivo» (2016a: 24).

\section{LOS PROGRAMAS DE DESRADICALIZACIÓN}

Los programas de radicalización se han tenido que enfrentar a una serie de problemas conceptuales desde el inicio. Y es que establecer un consenso en torno al significado que se les atribuía a los términos «radicalización» y «desradicalización», resulta esencial para testar la efectividad de los programas. Hay autores que defienden un modelo de asistencia y acompañamiento personalizado, como condición indispensable, en relación a cualquier intento de catalogar como "radicalizado" a un joven y acometer cualquier "proceso de desradicalización». El miembro de la Asamblea Nacional Sébastien Pietrassanta, autor de una ponencia relativa al proyecto de ley de lucha contra el terrorismo en 2015, basándose en la definición del alto funcionario de Defensa Pierre Conessa, afirma que «la radicalización implica una legitimación intelectual, filosófica y religiosa del tránsito a la violencia y la inserción en un nuevo grupo que aporta al individuo una identidad de sustitución y la sensación de una dignidad recuperada» (2015: 8-9). Asiem El Difraoui define la radicalización como un proceso «complejo y delicado» y que puede durar años, en el que es preciso desterrar ideas preconcebidas respecto a recetas milagrosas para acabar con ella. En todo caso, el acierto sobre el espacio en el que se van a producir las llamadas «medidas de desradicalización» resulta fundamental, ya que un enfoque basado exclusivamente en la seguridad puede conducir paradójicamente, a la estigmatización y comunitarización de los radicales (Pietrassanta, 2015: 23). En cualquier caso, parece obvio que no se puede acometer ningún proceso de desradicalización si antes no se ha comprendido bien cómo se ha generado la propia radicalización (Benslama, 2016a: 5). 
Respecto al modo en que se acomete un proceso de desradicalización, no existe un protocolo ideal. La desradicalización en cualquier caso, «no supone solamente que desaparezca la radicalización sino que se de un proceso de emancipación del radicalismo que implica la integración del individuo en la sociedad (Pietrassanta, 2015: 23 y 62). Burgat no creen en «enseñar a los jóvenes a interpretar el Corán de manera personal y no manipulada, en tanto que la radicalización no es ideológica sino política» (2016a). Otros como Olivier Roy muestran un total escepticismo ante los programas de desradicalización cuando expresa que «los jóvenes quieren radicalizarse. Si se les explica que eso está mal, lo van a desear aún más (2016: 37).

A continuación se va a exponer de manera somera los principales programas de desradicalización existentes en nuestro entorno institucional: la Unión Europea, dos países del entorno europeo más próximo como Reino Unido y Alemania, el Estado Español, y las Comunidades autónomas de Euskadi y Cataluña.

\subsection{Panorama general de los programas de desradicalización}

En la Unión Europea existe el programa Radicalisation Awareness Network - RAN- que se inició en el año 2011 por parte de la Comisión. El RAN se basa en el trabajo conjunto entre profesores, trabajadores sociales, ONGs, think-tanks y policía. En el 2015 se creó el Centre of Excellence que es el órgano coordinador de todo el programa. El RAN ha seleccionado una variedad de prácticas que ha reunido en siete campos diferentes. Cada uno de los siete tiene una metodología concreta. Se trata de extraer lecciones aprendidas de los programas que se aplican en el territorio de la Unión (Preventing Radicalisation, 2017: 13):

\section{Campos de actuación del RAN}

1. Formación de profesionales en primera línea: sensibilización de profesionales que trabajan con personas en riesgo de radicalización.

2. Estrategias de salida: programas de desradicalización para reintegrar a los extremistas violentos y disuadir a los que están en riesgo de radicalización.

3. Empoderamiento y participación comunitaria: empoderamiento de las comunidades de riesgo para que establezcan una relación de confianza con las autoridades.

4. Educación para los jóvenes: educación en ciudadanía, tolerancia religiosa, política y étnica, en un pensamiento sin prejuicios, contra el extremismo, y en valores democráticos, la diversidad cultural y las consecuencias históricas de la violencia étnica y de motivación política.

5. Apoyo familiar: para las familias de los jóvenes en riesgo de radicalización y para las de jóvenes radicalizados.

6. Elaboración de narrativas alternativas: ofrecer alternativas a la propaganda extremista bien en la red de internet o fuera de ella.

7. Estructuras multinivel: creación de redes interconectadas para asegurar que las personas en riesgo reciban un apoyo temprano.

Fuente: RAN. (2017). Preventing Radicalisation. 
El RAN no es un marco teórico. Aunque sus campos de acción se han basado en la literatura científica existente, su labor se desarrolla en base al trabajo empírico y la experimentación de programas. El RAN descarta la pretensión de alcanzar un perfil común del «radicalizado» para después elaborar teorías entorno a esa definición. La radicalización es el resultado de una combinación de factores relacionados con hechos de vida de la persona que la sufre. Desde este punto de vista se pregunta: ¿Cómo identificar a las personas vulnerables en riesgo de radicalización, teniendo en cuenta que no existe ningún checklist definitivo indicadores - para la radicalización? Por eso, la desradicalización conlleva un trabajo de confianza, conversación, paciencia e intervención multinivel y coordinada, desde la conciencia de que hay muchas instituciones implicadas para la respuesta a procesos complejos y en el que se precisan tanto la confidencialidad - con el radicalizado- como el intercambio de información sensible con las instituciones implicadas (2017: 13-14).

En el Reino Unido existe el programa Contest (2014) que se articula en cuatro programas con objetivos diferenciados: Prevent, Pursue, Protect y Prepare. En 2013 se puso en marcha también el programa Tarabiyah (2013) para luchar contra la radicalización en las prisiones. El modelo británico se caracteriza por la implicación de la red civil empleando actores de confianza de los jóvenes en el desarrollo de los programas. El programa Prevent es el que está dedicado específicamente a impedir que las personas lleguen a integrar las redes terroristas; garantiza que las personas en riesgo de radicalización reciban un apoyo personal y trabaja con los sectores específicos en riesgo de radicalización en los municipios (Contest, 2016: 15).

El Prevent británico ha desarrollado acciones como: la eliminación de material ilegal de terroristas en línea -más de 55.000 piezas en 2015-; se han tomado medidas para suspender las cuentas de quienes propagan páginas extremistas; ofrece formación para producir sitios web de contra-narrativa yihadista - las visitas en línea a estas páginas generaron más 15 millones de visitas en línea en 2015-; asesora a los tribunales de familia británicos para proteger a los menores en riesgo de radicalización en coordinación con las autoridades locales y la policía; implementa el programa Channel, que ha formado grupos de apoyo y discusión en los que se detectan a personas en riesgo de radicalización en cada municipio del Reino Unido; realiza una programación específica sobre los más de 1.000 presos en cárceles británicas en riesgo de radicalización; ha impartido formación sobre más de 150.000 trabajadores del sistema de salud británico; ha proporcionado asesoramiento y materiales de prevención a los padres y responsables escolares; ha desarrollado programas de acción comunitaria a nivel local para favorecer la resiliencia sobre jóvenes en riesgo de radicalización; ha dispuesto un fondo de beca de 3,6 millones de libras esterlinas para desarrollar nuevos planes de intervención preventiva a escala local y por último va a proceder a estudiar en el futuro un nuevo esquema de desradicalización para aquellas personas que necesitan un apoyo más intensivo (Contest 2016: 17-18).

En Alemania, basándose en la estrategia de años en la prevención contra las redes neonazis está el Violence, and Prevention Network desde 2014. El programa alemán se apoya 
también en la sociedad civil y engloba factores ideológicos, religiosos y emocionales y se basa en la atención temprana, para evitar el aislamiento social de los jóvenes. El Violence and Prevention Network se fundamenta en estrategias que buscan que los jóvenes se alejen de esquemas de pensamiento que pueden ser el inicio de un proceso de radicalización, por eso el programa busca «el alejamiento de patrones de pensamiento radicales, lo único que puede funcionar en un esquema de prevención sostenible». ${ }^{10}$ No se trata de buscar una oposición directa al esquema ideológico que puede afectar a los jóvenes sino de «buscar el cuestionamiento de su propia biografía en relación a problemas individuales que se les presentan». Por eso el aislamiento de grupos homogéneos en base a problemas comunes es un profundo error (2016: 12). Hay que recalcar que el programa alemán concede una gran importancia al establecimiento de redes coordinadas de intervención para lo que está integrado en el programa de la UE y creó una estructura propia internacional para compartir estrategias la European Network of Deradicalisation (ENoD).

En España existe el «Pacto antiyihadista» - Acuerdo para afianzar la unidad en defensa de las libertades y en la lucha contra el terrorismo- suscrito por el Presidente del Gobierno y el líder de la oposición, tras los atentados terroristas islamistas de enero de 2015 en Francia. Se trató de un acuerdo polémico puesto que fuerzas con representación parlamentaria como las minorías nacionalistas catalana y vasca y partidos importantes de ámbito estatal como Izquierda Unida y Podemos no llegaron a suscribirlo por diferentes razones. El acuerdo, consta de ocho puntos y uno de ellos trata sobre «Poner en marcha políticas activas eficaces en la erradicación de cualquier forma de radicalización violenta, incluidas las expresiones de racismo, xenofobia o discriminación, motivadas por la intolerancia respecto a distintas opiniones, creencias o confesiones religiosas».

El Ministerio del Interior designó al Centro de Inteligencia contra el Terrorismo y el Crimen Organizado — CITCO-, el desarrollo de un plan estratégico contra el terrorismo y la radicalización que eligió una comisión de representantes de 12 ministerios y del Centro Nacional de Inteligencia —CNI- para su elaboración. Finalmente el Ejecutivo aprobó el «Plan estratégico nacional de lucha contra la radicalización violenta» —PEN-LRV—. El objetivo del Plan se centra en «constituir un instrumento eficaz de detección temprana y neutralización de los brotes y focos de radicalismo violento, actuando sobre aquellas co-

\footnotetext{
10 El documento Deradicalisation, Intervention, Prevention de 2016 de la organización alemana incluye un ejemplo de intervención que expresa de manera gráfica el método preventivo que emplea Violence and Prevention Network: «La madre de H está sentada en el sofá de su sala de estar llorando. Ayer, encontró una maleta llena de cosas de su hijo. Había un billete a Estambul. La madre expresa: «Él nunca ha sido organizado y he encontrado todo doblado de manera perfecta.» El profesional del programa intenta calmarla. El desafío reside en la relación entre la madre y el hijo. Han estado semanas evitándose. "Está siempre en la mezquita» afirma la madre. El padre está fuera por motivos laborales y solo vuelve a casa los fines de semana. "¿Debemos solucionar el problema a base de prohibiciones?», se pregunta la madre. El profesional no juzga a los padres. Trabaja con la madre para que recupere el diálogo con su hijo pero lo importante es que este diálogo se lleve a cabo únicamente sobre temas triviales de la vida cotidiana. La cuestión religiosa debe evitarse de manera obligada. Aunque $\mathrm{H}$ está en casa, no quiere hablar de manera directa con el profesional. Al día siguiente, el profesional vuelva a casa y mete una carta para $\mathrm{H}$ por debajo de la puerta de su habitación. Es una invitación a dialogar. Una semana más tarde cuando el profesional está con la madre en casa, sale una nota por debajo de la puerta de H: «Quizás mañana». Es un comienzo.» (Violence and Prevention Network, 2016: 13)
} 
munidades, colectivos o individuos en situación de riesgo o vulnerabilidad» (PEN-LRV, 2015: 5). El Plan se estructura en tres áreas funcionales: área de prevenir —antes—; destinada a generar confianza social y a impedir la propagación de ideologías radicales y violentas; área de vigilar —durante —; diseñada para ejercer funciones de observación en el área local sobre procesos de radicalización incipiente y obstaculizarla; y área de actuar después-; enfocada al seguimiento de los individuos que legitimen la violencia terrorista (2015: 8). Como responsable máximo del Plan ha sido creado un órgano interministerial bajo la supervisión del Ministerio del Interior que está directamente conectado en cada municipio con un Grupo Local multisectorial (2015: 17).

Después de los atentados en la Rambla de Barcelona y Cambrils en agosto del 2017, el Plan recibió algunas críticas dado que dos años y medio después de su presentación, solamente 13 municipios de los 8000 que hay en España han puesto en práctica Grupos Locales. Del mismo modo, «altos mandos de la lucha antiterrorista achacan el escaso desarrollo del plan a la falta de voluntad política por todo lo que implica de coordinación entre administraciones y a que falta toda una parte técnica por desarrollar, como la creación de un software para poder compartir la información» (El País, 2017).

En Euskadi el Gobierno vasco constituyó en junio de 2017 un grupo de trabajo destinado a desarrollar una estrategia integral para prevenir la radicalización yihadista. Este grupo se desarrolla en el contexto del «Plan Integral contra el islamismo radical» que se realizó tras los atentados de París de 2015 por parte del Departamento de Seguridad del Gobierno Vasco que implica medidas específicas de formación para la policía autonómica y la mejora en la protección de la ciudadanía.

En Cataluña también se activaron en el seno de la policía autonómica una serie de protocolos a partir de 2015. En 2017 se ha realizado el «Plan de prevención, detección e intervención de procesos de radicalización en los centros educativos». Entre sus objetivos están; dar a conocer los riesgos personales, escolares, familiares y sociales que pueden llevar a un alumno a un proceso de radicalización; proporcionar a los centros educativos los recursos y orientación para prevenirlos; trabajar sobre los factores de riesgo y potenciar los factores asociados a la función docente (Prevenir, 2017: 5-6).

\subsection{Los programas de desradicalización en Francia: el centro de Pontourny}

En Francia, se han puesto en marcha, a partir de 2015, toda una serie de medidas relacionadas con el terrorismo yihadista: en enero de 2015, un Plan Antiterrorista; en noviembre, un Pacto de Seguridad; en mayo de 2016, el Plan contra la radicalización que referimos más adelante; en septiembre, un Plan de reinserción y ciudadanía; y en octubre, un Plan para la seguridad penitenciaria y contra la radicalización violenta en las cárceles. Mención especial requiere la puesta en marcha de la página web «Stop-Djihadisme» en febrero de 2015 como herramienta accesible a la ciudadanía — http://www.stop-djihadisme.gouv.fr/— 
donde puede consultarse la información relacionada con las medidas del gobierno francés para combatir la radicalización (Benbassa y Troendlé, 2017).

Según un informe de investigación para las políticas públicas del Instituto Montaigne del 2016, los ciudadanos musulmanes de Francia representan el 5.6\% de la población y alcanzan el número de 3 millones de habitantes. Hay que tener en cuenta las restricciones demoscópicas a las que se enfrentan este tipo de instituciones en Francia, por cuanto el Instituto de Estadística de Francia no facilita información censal en base a pertenencia étnica o religiosa, lo que provoca que las cifras de seguidores del islam en Francia fluctúe bastante de un estudio a otro. El estudio del Instituto Montaigne ha sido elaborado por Hakim El Karoui que fue asesor del exprimer Ministro Jean-Pierre Raffarin (2002-2005) y se realizó sobre una muestra de 15.459 entrevistas realizadas entre el 13 de abril y el 23 de mayo de 2016, sobre musulmanes franceses de entre 15 y 30 años (2016: 12).

El estudio estableció tres perfiles entre los musulmanes de Francia. Un primer grupo, denominado los «seculares», representan el $46 \%$ de la población musulmana. Son aquellos que aunque admiten que la religión es una parte importante en sus vidas, se consideran secularizados. En un segundo, estarían los «orgullosos del islam», que representan un $25 \%$. Estos se autodefinen principalmente como musulmanes y proclaman su observancia de la fe en público por medio del código de vestimenta femenina — hijab- y el código alimentario - halal—. A pesar de ello, rechaza los aspectos más rigoristas de la ley islámica en su sentido más estricto, el velo que cubre el rostro — niqab-y la poligamia, por cuanto dicen respetar el secularismo y las leyes republicanas francesas. Finalmente está el grupo calificado como «ultra» por los autores del estudio, que representa el 28\%. Afirman su voluntad de vivir ignorando los valores republicanos de manera explícita, para ellos la ley islámica — sharia —, es lo primero. Aprueban la poligamia y la vestimenta del niqab e incluso el burqa. La adhesión a la versión más rigorista del islam se ha convertido para este grupo en una forma de identidad y en sostén de su rebelión contra el sistema republicano. (2016: 18). Un dato significativo sobre este grupo es que es el predominante entre los jóvenes - el 50\% de los menores de 25 años-, lo que significa que uno de cada dos jóvenes franceses de la comunidad musulmana en la actualidad se adscribe al salafismo como ideario de ruptura (2016: 19).

El gobierno francés de Manuel Valls anunció en mayo de 2016 la puesta en marcha de manera experimental de "Centros de desradicalización» para jóvenes yihadistas y supervisados por el «Comité Interministerial para la Prevención de la delincuencia y la radicalización», con un presupuesto de 100 millones de euros. El primer ministro Valls aseguró que «la radicalización de los jóvenes era el reto más serio al que se enfrentaba el país desde la Segunda Guerra Mundial» (Le Monde, 2016a), y anunció en septiembre de 2016 la apertura del Centro de Pontourny, en el municipio de Beaumont-en-Véron en el Departamento Indre-Loire - Región del Valle del Loire- El centro contó con la supervisión de expertos como Gerald Bronner o Fehti Benslama y debía servir como modelo para otros 13 centros, uno en cada región metropolitana y dependientes del «Centro de Prevención, inserción y 
de ciudadanía». El objetivo del gobierno era que en dos años 3600 jóvenes radicalizados ingresaran en los centros (Le Monde, 2016a).

El Centro de Pontourny, proyectado como programa de desradicalización experimental, tuvo una capacidad para acoger 25 personas de entre 18-30 años y contó con una plantilla de 27 profesionales: 5 psicólogos, un enfermero psiquiátrico y 9 educadores especializados. La selección de jóvenes se realizó en base a la información policial proporcionada por la Unidad de coordinación de la lucha antiterrorista de París, que desde 2015 tenía en sus bases de datos, a 1200 jóvenes radicalizados (Benbassa y Troendlé, 2017: 2). Seis meses después de la apertura del centro piloto, en febrero de 2017, se procedió a celebrar una sesión de evaluación del rendimiento del Centro de Pontourny en el Senado. Según el informe elaborado por las senadoras Esther Benbassa y Catherine Troendlé, Pontourny acogió en el periodo de su mayor apogeo a 9 jóvenes. En febrero de 2017, solo quedaba una persona en el centro y con la condena del joven a 4 meses de prisión por apología del terrorismo, a finales de mes, quedó vacío (2017: 3). Debido a las salidas anticipadas, ninguno de los participantes cumplió la fase de estancia programada de 10 meses, no llegando a alcanzar nadie los 5 meses de estancia. El eco mediático que tuvo la apertura del centro propició también un clima contrario en la población local, algo que contribuyó a la estigmatización de los internos y a las protestas por su alto coste -2,5 millones-, en un clima de progresiva eliminación de servicios sociales de ámbito local (2017: 12).

El informe del senado plantea algunas lecciones de la experiencia que ponen seriamente en cuestión la eficacia de la misma. La elección de un medio aislado no favoreció el éxito del programa y una serie de medidas obligatorias para los internos para una educación «republicana», y de gran contenido mediático, y de marketing, como el estudio de la historia de Francia, honrar la bandera nacional y cantar la marsellesa una vez por semana resultaron estériles. El aislamiento de los internos propició la influencia de los líderes sobre otros internos que abandonaron el centro más contaminados a cómo habían entrado (2017: 5). De forma paralela al centro de Pontourny, se llevó a cabo un programa piloto destinado a crear unidades de prevención de la radicalización en las prisiones de Fresnes, Fleury-Mérogis, Osny y Lille-Annoeullin. Las estadísticas mostraron también que el aislamiento propició la radicalización grupal y no se consiguieron los objetivos propuestos en las cárceles (2017: 5). Del mismo modo, se utilizaron las bases de datos de unidades policiales para catalogar a la población «radical» y seleccionarla como interna en el centro de desradicalización. Se consideraron radicalizados a los jóvenes que se hallaban en las bases de datos policiales sin conocer su historia personal, simplemente por figurar como sospechosos.

El Senado en un último informe del 12 de julio de 2017 descarta de manera definitiva la puesta en marcha centros de desradicalización como el de Pontourny y en un listado de 10 propuestas de actuación, destaca 5 en relación a las políticas de desradicalización en el futuro (Benbassa y Troendlé 2017a: 5): 
1. Seleccionar las organizaciones que se encargan de procesos de desradicalización en Francia y sistematizar la evaluación del contenido de su actividad. Reducir el número de programas y optar por la calidad y no por la cantidad.

2. Mejorar la formación de los actores públicos en relación a la radicalización y definir los objetivos y delegar el trabajo en aquellas estructuras que se están mostrando eficaces.

3. Poner fin a la prueba del centro, inserción y ciudadanía de Pontourny y a su extensión.

4. Promover en la lucha contra la radicalización elementos como la personalización, las redes de apoyo, la transversalidad y la apuesta por el equilibrio entre la intervención social y la seguridad.

5. Establecer redes interactivas para compartir experiencias con otros países.

El informe de julio del Senado pretende reorientar las políticas de prevención a favor de dispositivos de proximidad para mejorar el contenido de los programas de desradicalización (2017a: 39). Frente al modelo fallido del centro de Pontourny basado en el aislamiento, el informe pone su atención en los programas de Vilvorde (Bélgica) y Aarhus (Dinamarca). En ambos casos los jóvenes radicalizados son intervenidos sin separarlos del hogar familiar. El informe se hace eco que la intervención de proximidad permite la integración social y laboral de las personas radicalizadas como un elemento fundamental para evitar la recaída en conductas extremistas (2017a: 43). La proximidad permite en estas ciudades la cooperación entre servicios sociales y policía, la involucración de la familia y el empleo de la red sociocomunitaria del joven radicalizado como factores de apoyo en la estrategia contra la radicalización. Los programas belga y danés apuestan también por el intercambio fluido de información entre la escuela y los servicios de salud. (2017a: 46). Tanto senadores como expertos reivindican la restitución de la red de servicios sociales en Francia en el ámbito de la protección infantil y juvenil y la prevención coordinada con la escuela (Benbassa y Troendlé, 2017; Benraad, 2016 y 2017) como requisito de personalización sobre el que debe pivotar cualquier programa en el futuro (Nabaskues 2003). Además de al esquema de intervención de los programas señalados, el informe alude al menor coste de los mismos en comparación al programa francés.

El Senado extrae una serie de conclusiones de la experiencia de Pontourny (Benbassa y Troendlé 2017a: 81):

- La tipología de los terroristas tiene una gran diversidad pero la mayoría proviene de segmentos sociales desfavorecidos y el mundo de la delincuencia. Esto implica una reflexión urgente sobre las políticas urbanas en los suburbios, la creación de planes para reducir el desempleo, contra el abandono escolar, la creación de una policía de proximidad, y el apoyo a asociaciones civiles en los suburbios. 
- Hay que tener en cuenta que el comportamiento sectario de los radicalizados se relaciona con la búsqueda de una nueva personalidad radical y vinculada al islam.

- La respuesta a la radicalización requiere respuestas múltiples y no solo represivas que tengan como objetivo el acompañamiento personalizado y poner el acento en la rehabilitación.

El contexto post-atentados propició en Francia una lógica utilitarista y de corto plazo de los planes de desradicalización puestos en marcha en 2016 (Bonnefoy, 2016). Han sido elaborados desde la precipitación y en un clima de ansiedad general que ha llevado al gobierno a una actuación condicionada por el pánico creado por los atentados (Benbassa y Troendlé, 2017), y fueron anunciados a bombo y platillo en los medios de comunicación, lo que refleja que el gobierno se instaló en una visión cortoplacista centrada en extender en el país la sensación de que tenía el problema bajo control. El discurso institucional se ha enfocado en la línea de la seguridad pública, primando la metodología y presupuestos de esta lógica como postulados de investigación científica (Bouzar, 2016a: 5).

Muriel Domenach, la responsable del programa del gobierno, señala que los informes del senado marcan el final de los grandes proyectos de desradicalización en Francia, y aunque defiende la experiencia de Pontourny, de la que se han podido extraer valiosas conclusiones, afirma que los programas en el futuro deben centrarse en la prevención y la coordinación de los servicios sociales y educativos en red. El enfoque multidisciplinar (social, psicológico y educacional) deberá ser el paradigma de estos programas en base al método ensayo-error y buscando guiar a los profesionales sobre herramientas flexibles de intervención como manuales de buenas prácticas (Domenach, 2017a). En la misma línea, el colaborador del programa gubernamental Fehti Benslama señala como un factor clave, el aprovechamiento de la red de servicios sociales por encima de grandes planes de acción a escala nacional en los que se preste formación especializada a psicólogos, educadores y trabajadores sociales y manifiesta una sentencia concluyente y reveladora sobre el programa del gobierno: «cuando se ha creado y etiquetado un centro como de «desradicalización», los jóvenes han optado por abandonarlo» (2016a: 5).

\subsection{El programa CAPRI de Burdeos}

Una vez constatado el fracaso del programa de desradicalización del gobierno francés, los responsables institucionales han vuelto a situar la mirada en las asociaciones civiles. Ya hemos visto las líneas maestras del programa de desradicalización del CPDSI de Dounia Bouzar, que en fechas recientes se desvinculó de los contratos que mantenía con el gobierno por poner en marcha acciones restrictivas de los derechos fundamentales contra personas inmigrantes. Vamos a analizar las líneas maestras del programa de desradicalización de la ciudad de Burdeos, al que Muriel Domenach, la responsable de desradicalización del gobierno, alude como ejemplo de buena práctica a tener en cuenta como modelo de futuro (2017a). 


\section{Organización}

El centro CAPRI abierto en enero de 2016, trabaja en el ámbito de la prevención tratando de reparar los factores de radicalización y basa su estrategia en evitar la estigmatización y aislamiento de los jóvenes y sus familias. El centro de Burdeos favorece, al igual que el CPDSI, el espacio para la autonomía del individuo, respetando su proceso evolutivo.

La misión de la intervención de CAPRI, se basa en tres pilares: desmontar el discurso yihadista de internet, formar el personal de servicios sociales y educativos para favorecer la detección precoz y el uso de herramientas de prevención secundaria para actuar ante los primeros indicadores de radicalización. El centro trabaja en coordinación con psiquiatras y profesionales contra las actividades sectarias en la ciudad y con instituciones como el Ayuntamiento o la Federación musulmana de la Gironde. Para CAPRI la radicalización es un fenómeno polimorfo por lo que es preciso individualizar la intervención caso por caso. El método de intervención de CAPRI trabaja sobre la base de la definición de radicalización de Farhad Khosrokhavar mencionada en líneas anteriores (Fetouh, 2016).

El presupuesto es financiado por la Prefectura y el Comité Interministerial para la prevención de la delincuencia, por las autoridades locales territoriales -Ayuntamiento de Burdeos, Consejo General de Gironda y Consejo Regional de Nueva Aquitania- y el Servicio Judicial de Protección infantil y juvenil. Los locales y los recursos son sufragados por Bordeaux Metropole, la Metropoli surgida como consecuencia de la Ley de modernización administrativa aprobada en Francia en 2015 (European Forum, 2017: 4).

\section{Modelo de intervención}

La acción preventiva de CAPRI está organizada según la categorización clásica de prevención: acciones de prevención primaria y acciones de prevención secundaria.

Entre las actividades de prevención primaria se pueden destacar las siguientes:

- Acciones de contra-discurso en internet contra las técnicas de manipulación mental por medio de argumentos extremistas y la teoría de la conspiración.

-Formación de activistas del ámbito social y juvenil para la detección de casos de radicalización. Los cursos están orientados a que las personas que intervienen con jóvenes radicalizados adopten un enfoque de intervención no estigmatizador, y que reduzcan la tensión mediante el diálogo a la vez que promueven el conocimiento sobre los factores de radicalización.

- Intervención psicosocial mediante audiencias sociales con personas radicalizadas o en riesgo de radicalización. 
Entre las actividades de prevención secundaria destacamos:

—Apoyo psicosocial por medio de psiquiatras y psicólogos especializados.

— Apoyo con expertos en teología llegado el caso.

Se trabaja con una lógica de caso. El caso entra en CAPRI por mail, teléfono o por iniciativa de cualquier interesado, amigo o familiar directo de la persona en cuestión. Inicialmente, el equipo informa y acompaña a la persona en su demanda de ayuda, que es voluntaria y se ejerce de manera estrictamente confidencial. La célula de evaluación multidisciplinar realiza un análisis para determinar si existen señales significativas de radicalización y propone el tipo de intervención más adecuado. Si considera que existen elementos que sugieren un peligro inmediato para la seguridad individual o pública, la asociación informa a las autoridades competentes, empleando para ello un protocolo específico (European Forum, 2017: 2).

Se emplean tres tipos de indicador (Fetouh, 2016: 27-29):

\begin{tabular}{|l|}
\hline \multicolumn{1}{|c|}{ Indicadores no significantes de radicalización } \\
\hline - Sostener las convicciones de manera ferviente \\
\hline - Expresar la identidad o afiliación religiosa de manera visible \\
\hline - Abogar pacíficamente por una causa vinculada a una visión grupal \\
\hline - Mostrar un interés especial en asuntos de actualidad nacional o internacional \\
\hline - Expresar una voluntad de integrarse o profundizar en prácticas religiosas o políticas \\
\hline - Adoptar nuevas creencias que no van contra la convivencia \\
\hline
\end{tabular}

Fuente: Fetouh, M. (2016). CAPRI. La prévention de la radicalisation.

\begin{tabular}{|l|}
\multicolumn{1}{c|}{ Indicadores preocupantes de radicalización } \\
\hline — Adhesión a teorías conspirativas \\
\hline - Discursos paranoides, antisociales o antisemitas \\
\hline - Obsesión con discursos mesiánicos como los que anticipan el fin del mundo \\
\hline - Aislamiento del grupo de amigos o espacios de ocio habitual y frecuentación exclusiva de nue- \\
vas amistades (CAPRI discrimina este indicador como un indicador fundamental) \\
\hline - Fragilidad psicológica o social, desestructuración familiar \\
\hline - Antecedentes judiciales
\end{tabular}

Fuente: Fetouh, M. (2016). CAPRI. La prévention de la radicalisation. 


\begin{tabular}{|l|}
\hline \multicolumn{1}{|c|}{ Indicadores muy preocupantes de radicalización } \\
\hline - Estrategia de ocultación de creencias religiosas y de signos externos de pertenencia \\
\hline - Ruptura profesional, escolar o familiar \\
\hline - Legitimación de la violencia para sostener una causa o ideología \\
\hline - Discursos deshumanizadores de otros colectivos o individuos \\
\hline - Frecuentación de personas radicalizadas en proximidad o por internet \\
\hline - Consulta de lugares o foros telemáticos radicales \\
\hline
\end{tabular}

Fuente: Fetouh, M. (2016). CAPRI. La prévention de la radicalisation.

\section{Proceso de Intervención de CAPRI}

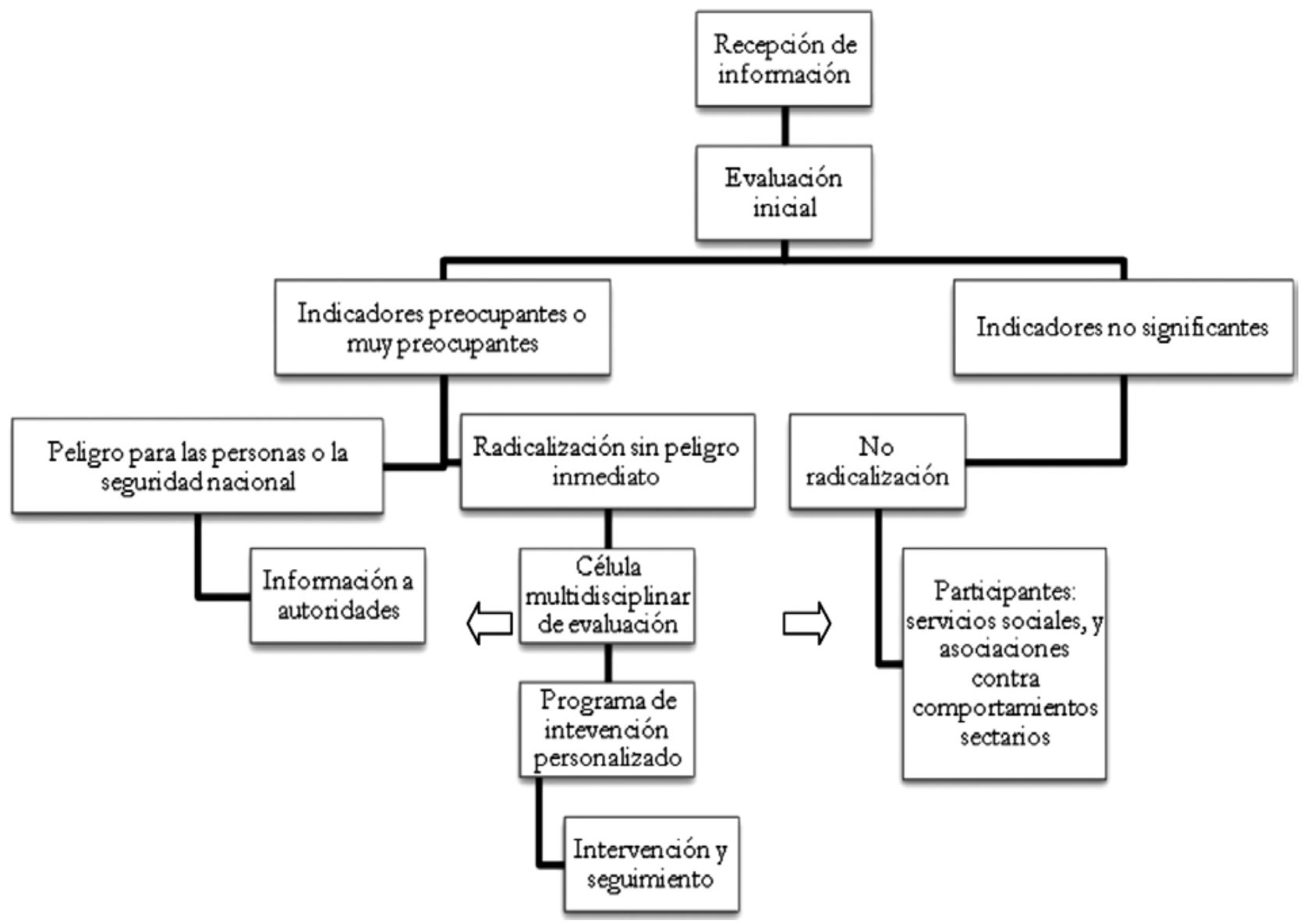

Fuente: Fetouh, M. (2016). CAPRI. La prévention de la radicalisation.

Como se puede ver en el cuadro, CAPRI desarrolla el programa siguiendo un itinerario personalizado en el que la utilización de los tres tipos de indicadores referidos condiciona el trabajo de desradicalización. La derivación policial solo se produce en un primer momento, en los casos de aparición de indicadores muy preocupantes. En el caso de aparición de indicadores no significantes pueden llevarse a cabo actividades de diálogo intrafamiliar o de sesiones de sensibilización adaptadas al caso. En caso de detectarse indicadores de radicalización sin peligro inmediato se pone en marcha el verdadero trabajo interdisciplinar. 


\section{Resultados y evaluación}

Desde su lanzamiento en enero de 2016, CAPRI actuó sobre 33 casos en el ámbito de prevención secundaria —a fecha de 7 de septiembre de 2016-. En paralelo a las intervenciones del grupo, la organización ha prestado labores de formación en otras instancias territoriales del país. En el ámbito de prevención primaria casi 800 personas, principalmente profesionales, han colaborado con CAPRI sobre distintos campos de intervención. Asimismo el video divulgativo elaborado por la asociación fue visitado por más de 400.000 personas durante el año 2016. Los responsables de la organización expresan que aún es pronto para poder acometer una evaluación cualitativa de todas las acciones de la organización. No obstante se expresa que han sido capaces de poner en marcha el modelo de intervención, que ha sido posible ejecutar en todos los casos atendidos (European Forum, 2017: 4-5).

Respecto a la evaluación de la intervención en prevención primaria, los módulos formativos que se imparten están trabajados y adaptados en base a hojas de evaluación devueltos por los participantes. El video divulgativo colgado en la página web de la asociación ha sido el primer test para evaluar el impacto de las herramientas telemáticas. Tras el éxito del video experimental sobre el tema de la lucha contra la propaganda yihadista, la organización se ha comprometido a producir un segundo video de similares características (2017: 4-5).

Las perspectivas de la asociación son dos: desarrollar una formación común que incluya a los profesionales identificados como importantes para el trabajo en el territorio de la Gironde y ayudar a construir una cultura común en el fenómeno de la prevención de la radicalización en su territorio (2017: 5).

En prevención secundaria, el equipo de CAPRI evalúa mensualmente los casos de intervención. Desde un punto de vista global, seis meses después del lanzamiento de la estructura, fue presentado un informe interno en la reunión general de la asociación. A finales del 2016 la asociación considera prematuro establecer conclusiones de unas acciones cuyo impacto y resultados se observarán con el tiempo. Se establece como línea prioritaria en el futuro fortalecer la alianza con los servicios judiciales de protección juvenil (2017: 5).

Resulta paradójico, que la máxima responsable del programa gubernamental señale el centro de prevención de Burdeos de CAPRI como ejemplo de cómo se deben abordar procesos de desradicalización en el futuro, sobre lógicas de prevención primaria y secundaria y siempre en un contexto en red y multidisciplinar, precisamente en el sentido inverso al programa del gobierno que ha descansado en las lógicas de seguridad y segregación espacial. El fracaso del programa del gobierno marca un horizonte para el abordaje del fenómeno de la radicalización yihadista en el futuro que deberán ajustarse a otros parámetros de intervención social más centrados en la prevención que en la seguridad como muestra el caso de Burdeos. 


\section{CONCLUSIONES}

En este artículo se han recogido los fenómenos sociales más significativos que según algunos de los expertos más reputados explican la explosión radical yihadista juvenil en Francia. Si bien todos aluden a las brechas sociales en los suburbios de las principales ciudades del país como un factor fundamental de donde se nutre el yihadismo, las tesis que se inscriben en una lógica endógena de la sociedad francesa - Kepel y Roy-difieren sobre matices importantes respecto de aquellas que explican el fenómeno de la violencia como una consecuencia directa de procesos políticos internacionales y decisiones erróneas en torno a los mismos - Burgat y Filiu-. Otros autores, que se nutren de los mismos argumentos estructurales, se apoyan asimismo en elementos psicológicos de los jóvenes adolescentes en busca de identidades fuertes de sustitución -Benslama- o la estancia en prisión y el odio a la sociedad - Khosrokhavar - como factores importantes de ingreso en las redes yihadistas.

Se puede vislumbrar, a la luz de los datos expuestos en el artículo, que la radicalización, implica un proceso de reclutamiento relacional e ideológico - Bouzar- que acarrea una serie de rupturas biográficas severas con la escuela, trabajo, entorno social y familia. El modelo de radicalización del CPDSI articulado en cuatro fases muestra un itinerario visible de la radicalización. El acercamiento realizado a los programas de desradicalización europeo (RAN), británico (Prevent), alemán (Violence and Prevention Network), estatal $(P E N-L R V)$ y los nuevos planes de Euskadi y Catalunya muestran un creciente interés y esfuerzo por la implantación de programas en nuestro entorno institucional. En todo caso, y aunque algunos países están por delante de otros en lo que se refiere a la lucha contra la radicalización, la adaptación y la atención personalizada y en red serán los ejes sobre los que van a pivotar los programas en el futuro aunque estamos aún, como sostiene la literatura, en una fase de ensayo, experimentación y aprendizaje.

Con los dos casos de Francia, se ha podido comprobar que el programa de desradicalización del gobierno se ha basado en una lógica nacional-central, primando el establecimiento de espacios segregados como el centro de Pontourny y las unidades aisladas en las cárceles, pero esa segregación no ha dado sus frutos y la racionalidad sistémica desde la que se ha orientado no ha resultado operativa. Los informes de evaluación del Senado francés concluyen que la atención temprana y sobre la lógica de itinerarios personalizados y desarrollados en el propio contexto de los jóvenes es la base sobre la que debe enfrentarse la política de desradicalización en el futuro. Aún es pronto para extraer conclusiones de gran calado sobre la intervención de la asociación bordelesa CAPRI, pero el programa de la ciudad de Burdeos es interesante porque representa el paradigma sobre el que pueden basarse otros programas institucionales franceses en adelante. 


\section{REFERENCIAS BIBLIOGRÁFICAS}

Ali Adraoui, M. (2013). Du Golfe aux banlieues : le salafisme mondialisé. Paris: PUF.

Ali Adraoui, M. (2015a). Sociología de los yihadistas contemporáneos. Afkar ideas: Revista trimestral para el diálogo entre el Magreb, España y Europa, n. ${ }^{\circ}$ 45, pp. 18-20.

Benbassa T. y Troendlé C. (2017). Informe de evaluación del Senado sobre los programas de desradicalización en Francia, 12 de enero de 2017, disponible en http://www.senat.fr/rap/r16-438/r16-4380.html\#toc4

Benbassa T. y Troendlé C. (2017a). Informe de evaluación del Senado sobre los programas de desradicalización en Francia, 12 de julio de 2017, disponible en http://www.senat. fr/espace_presse/actualites/201707/rapport_final_de_la_mission_dinformation_sur_ le_desendoctrinement_le_desembrigadement_et_la_reinsertion_des_djihadistes_en_ france_et_en_europe.html

Benslama, F. (2014). La guerre des subjectivités en Islam. Paris : Lignes.

Benslama, F. (2015). Pour les désespérés, l'islamisme radical est un produit excitant. Disponible en http://www.lemonde.fr/societe/article/2015/11/12/pour-les-desesperes-lislamisme-radical-est-un-produit-excitant_4808430_3224.html

Benslama, F. (2015a). L’idéal blessé et le Surmusulman. En Benslama, F. (eds)., (pp 1-28). L’ideal eta la cruauté. Subjectivité et politique de la radicalisation. Paris : Lignes.

Benslama, F. (2016). Un furieux désir de sacrifice. Le surmusulman, Paris: Seuil.

Benslama, F. (2016a). Les resorts de la radicalization et de son traitement, Observatoire de la fraternité, Saint-Denis, París, 5 de octubre de 2016, disponible en http://observatoirefraternite93.org/wp-content/uploads/2017/01/CR-Fethi-benslamaderadicalisation.pdf

Benslama, F. (2017). Beaucoup de terroristes ne sont pas fous. France Inter Radio. Disponible en https://www.franceinter.fr/emissions/l-invite-de-8h20/l-invite-de-8h20-23aout-2017

Benraad, M. (2016). French Men attracted To 'Anti-sistem Utopia, disponible en http:// www.npr.org/2016/07/19/486646224/french-men-attracted-to-anti-system-utopia-indrive-to-join-isis

Benraad, M. (2017). L'Etat islamique, c'est l'irruption de reliquats de la tradition dans une hypermodernité, disponible en http://www.liberation.fr/debats/2017/06/02/myriam- 
benraad-l-etat-islamique-c-est-l-irruption-de-reliquats-de-la-tradition-dans-une-hypermoderni_1574195

Bertho, Alain (2016). Les enfants de chaos. Essai sur le temps des martyrs. Paris: La Découverte.

Bonnefoy, L. (2016). Des islamogues contre l'organisation de l'État islamique, disponible en http://orientxxi.info/magazine/des-islamologues-contre-l-organisation-de-l-etatislamique,1315,1315

Bouzar, D. (2016). Méthode expérimentale de déradicalisation, quelles stratégies émotionnelles et cognitives? Pouvoirs: Revue française d'etudes constitutionnelles et politiques, (La lutte contre le terrorisme), pp. 83-96.

Bouzar, D. (2016a). Despegarse de las redes yihadistas. Mente y cerebro, n. ${ }^{\circ}$ 76, pp. 18-25.

Bouzar, D. y Martin, M. (2016b). Pour quels motifs les jeunes s'engagent-ils dans le djihad ? Centre de prévention contre les dérives sectaires liées à l'islam (CPDSI).

Bronner, G. (2016a). Globalement, les terroristes jihadistes sont psychologiquement normaux, disponible en http://rmc.bfmtv.com/emission/gerald-bronner-les-terroristesjihadistes-sont-psychologiquement-normaux-941438.html

Bronner, G. (2016a). La théorie du complot est un marchepied à la radicalisation djihadiste, disponible en http://www.lejdd.fr/Societe/La-theorie-du-complot-est-un-marchepieda-la-radicalisation-djihadiste-789945

Bronner, G. (2016b). La pensée extrême. Comment des hommes ordinaires deviennent des fanatiques. Paris : Denoël.

Boukhobza, A. (2015). De la construction imaginaire du juif dans le discours islamiste extrême. En Benslama, F. (eds.) (pp 120-130). L’ideal eta la cruauté. Subjectivité et politique de la radicalisation. Paris : Lignes.

Burgat, F. (2010). Salafistas contra Hermanos Musulmanes. Le Monde Diplomatique en español, n. ${ }^{\circ} 177$, p. 6.

Burgat, F. (2016). Comprendre l'islam politique: une trajectoire de recherche sur l'altérité islamiste, 1973-2016. Paris: La Découverte.

Burgat, François. (2016a). Comparecencia en el Senado francés, 12 de enero de 2016, disponible en https://www.youtube.com/watch?v=cbRnWMP9fr4 
Castien Maestro, J.I. (2013). Las corrientes salafíes. Puritanismo religioso, proselitismo y militancia. Cuadernos de estrategia, n. ${ }^{0} 163$, pp. 117-154.

Contest. The United Kingdom's Strategy for Counter Terrorism. (2016). Annual Report for 2015. Home Office. British Government. Disponible enhttps://www.gov.uk/ government/uploads/system/uploads/attachment_data/file/539683/55469_Cm_9310_ Web_Accessible_v0.11.pdf

Dakhli, L. (2016). L'islamologie est un sport de combat. Revue du Crieur, n. ${ }^{\circ}$ 3, pp. 24-26.

Departament d'Ensenyament. Generalitat de Catalunya. (2015). Prevenció, detecció i intervenció de processos de radicalització als centres educatius. Disponible en http:// educacio.gencat.cat/documents/PC/ProjectesEducatius/PRODERAI-CE.pdf

Domenach M. (2017). Contre la radicalisation, il faut se concentrer sur la prévention, disponible en http://www.lemonde.fr/idees/article/2017/03/15/muriel-domenachcontre-la-radicalisation-il-faut-se-concentrer-sur-la-prevention_5094655_3232.html\# To3pDhw6th4QKGeQ.99

Domenach M. (2017a). Prevention de la radicalisation: Muriel Domenach rèpond aux polémiques, disponible en http://www.lagazettedescommunes.com/490888/preventionde-la-radicalisation-muriel-domenach-repond-aux-polemiques/

El Difraoui, A. (2014). El yihad de la imagen, Afkar ideas: Revista trimestral para el diálogo entre el Magreb, n. ${ }^{\circ}$ 43, pp. 24-26.

El País, 28 de agosto de 2017. Disponible en https://politica.elpais.com/politica/2017/08/28/ actualidad/1503946491_613708.html

European Forum for Urban Security. (2016). Fiche de practique. Centre d'action et prevention contre la radicalization des individus (CAPRI). Disponible en https://efus.eu/ files/2016/09/PS_Bordeaux_pr\%C3\%A9vention-radicalisation_FR.pdf

Fetouh, M. (2016). CAPRI. La prévention de la radicalisation. Disponible en http://www. vienne.gouv.fr/content/download/9711/68196/file/Pr\%C3\%A9sentation\%20M.\%20 FETOUH.pdf

Filiu, J.P. (2015a). Califato del terror a las puertas de Europa. Política Exterior, Vol. 29, n. ${ }^{\circ} 164$, pp. $64-70$.

Filiu, J.P. (2015b). Las redes yihadistas a la luz de "Charlie Hebdo», Afkar ideas: Revista trimestral para el diálogo entre el Magreb, n. ${ }^{\circ}$ 45, pp. 16-17. 
Fishman, S. (2010). Community Level Indicators of Radicalization: A Data and Methods Task Force. National Consortium for the Study of Terrorism and Responses to Terrorism. Department of Homeland Security Science and Technology Center of Excellence, University of Maryland. Disponible en https://www.start.umd.edu/pubs/START_ HFD_CommRadReport.pdf

Home Affairs Committee. (2016). Radicalisation: the counter-narrative and identifying the tipping point. House of Commons. Disponible en https://publications.parliament.uk/ pa/cm201617/cmselect/cmhaff/135/135.pdf

Instituto Español de Estudios Estratégicos (2014). Mustafá Setmarian. El ideólogo de la yihad moderna. Madrid. Ministerio de Defensa.

Institut Montaigne (2016). Un Islam francais est possible. Paris : Institut Montaigne.

Kepel, G. (2016). El terror entre nosotros. Una historia de yihad francesa (traducción Silvia Furió). Barcelona: Península.

Kepel, G. (2016a). La fracture. Paris: Gallimard.

Kepel, Gilles. (2016b). Radicalisations et islamophobie: le roi est nu, disponible en http://www. liberation.fr/debats/2016/03/14/radicalisations-et-islamophobie-le-roi-est-nu_1439535

Kepel, G. (2016c). L’Europe face au terrorisme. Revue politique et parlementaire, n. ${ }^{\circ} 1079$, (L’Europe dans la tourmente), pp. 75-78.

Khosrokhavar, F. (2014). Radicalisation. Paris : Maison des Sciences de l’Homme.

Khosrokhavar, F. (2015). Francia. Las nuevas clases medias musulmanas y su alienación. Vanguardia dossier, n. ${ }^{\circ}$ 56, pp. 64-69.

Khosrokhavar, F. (2015a). Le héros négatif. En Benslama, F. (eds)., (pp 30-45). L’ideal eta la cruauté. Subjectivité et politique de la radicalisation. Paris : Lignes.

Khosrokhavar, F. (2016). Prisons de France. Violence, radicalisation, déshumanisation : surveillants et détenus parlent, Paris : Robert Laffont.

Le Monde, 11 de febrero de 2016, disponible en http://www.lemonde.fr/societe/ article/2016/02/11/dounia-bouzar-renonce-a-sa-mission-sur-la-deradicalisation_ 4863906_3224.html

Le Monde, 9 de mayo de 2016a, disponible en http://www.lemonde.fr/societe/ article/2016/05/09/manuel-valls-doit-annoncer-ses-mesures-contre-la-radicalisationdjihadiste_4915701_3224.html 
Nabaskues, I. (2003). Globalización y nueva política local. Bilbao: Instituto Vasco de Administración Pública.

Neumann, Peter R. (2015). Victims, Perpetrators, Assets: The Narratives of Islamic State Defectors. The International Centre for the Study of Radicalisation and Political Violence. Disponible en http://www.ceskatelevize.cz/ct24/sites/default/files/1627584icsr-report-victims-perpertrators-assets-the-narratives-of-islamic-state-defectors.pdf

Pietrassanta, S. (2015). La déradicalisation, outil de lutte contre le terrorisme. Repporteur du project de la loi relatif á la lutte contre le terrorisme. Assemblée Nationales, Paris.

Radicalisation Awareness Network (RAN). (2017). Preventing radicalisation to Terrorism and Violent Extremism. Approaches and practices. Disponible en https://ec.europa. eu/home-affairs/sites/homeaffairs/files/what-we-do/networks/radicalisation_ awareness_network/ran-best-practices/docs/ran_collection-approaches_and_ practices_en.pdf

Roy, Olivier (2015). Le djihadisme est une révolte générationnelle et nihiliste. Le Monde (ensayo en separata), 24 de noviembre de 2015.

Roy, O. (2016). La djihad et le mort. Paris : Seuil.

Roy, O. (2016a). Peut-on comprendre les motivations des djihadistes? Pouvoirs: Revue française d'etudes constitutionnelles et politiques, n. 158 (La lutte contre le terrorisme), pp. 15-24.

Schmid, A. (2013). Radicalisation, De-Radicalisation, Counter-Radicalisation: A Conceptual Discussion and Literature Review. International Centro for Counter-Terrorism, The Hague. Disponible en https://www.icct.nl/download/file/ICCT-Schmid-RadicalisationDe-Radicalisation-Counter-Radicalisation-March-2013.pdf

Schuurman, B., Flower, S. (2016). Converts and Islamist Terrorism: An Introduction. International Centre for Counter-Terrorism, The Hague. Disponible en https://www.icct. nl/wp-content/uploads/2016/06/ICCT-Schuurman-Grol-Flower-Converts-June-2016. pdf

Secretaría de Estado de Seguridad. Ministerio del Interior (2015). Plan estratégico nacional de lucha contra la radicalización violenta: un marco para el respeto y el entendimiento común. Disponible en http://www.interior.gob.es/documents/642012/5179146/ PLAN+DEFINITIVO+APROBADO.pdf/f8226631-740a-489a-88c3-fb48146ae20d

Suárez Ballester, Juan Marcos (2016). El pensamiento salafista yihadista y su concepto de yihad. Revista de Relaciones Internacionales, Vol. 126, Septiembre-Diciembre, pp. 65-96. 
Thompson, R.L. (2011). Perspectives on Radicalization and Involvement in Terrorism. Radicalization and the use of social media. Journal of Strategic Security. Number 4, Volume 4, n. ${ }^{\circ}$ 4. Henley-Putnam University, California. Disponible enhttp:// scholarcommons.usf.edu/jss/vol4/iss4/

Van Prooijen, J.W., Krouwell A.P.M., Pollet, T.V. (2015). Political Extremism Predicts Belief in Conspiracy Theories, Social Psychological and Personality Science, Vol. 6, Issue 5, pp. 570-578.

Vidino, L., Brandon, J. (2012). Countering Radicalization in Europe. International Centre for the Study of Radicalisation and Political Violence. Disponible en http://icsr.info/wpcontent/uploads/2012/12/ICSR-Report-Countering-Radicalization-in-Europe.pdf

Violence and Prevention Network. (2016). Deradicalisation, Intervention, Prevention. Berlín. Disponible en http://www.violence-prevention-network.de/en/publications

Wilnera, Alex S., Duboulozb C. (2010). Homegrown terrorism and transformative learning: an interdisciplinary approach to understanding radicalization. Global Change, Peace \& Security. Vol. 22, No. 1, pp. 33-51. Disponible en http://www.tandfonline. com/doi/full/10.1080/14781150903487956 